\title{
Identification of Cdca7 as a novel Notch transcriptional target involved in hematopoietic stem cell emergence
}

\author{
Jordi Guiu, ${ }^{1}$ Dylan J.M. Bergen, ${ }^{1}$ Emma De Pater, ${ }^{2}$ Abul B.M.M.K. Islam,,${ }^{3,4}$ \\ Verónica Ayllón, ${ }^{5}$ Leonor Gama-Norton, ${ }^{1}$ Cristina Ruiz-Herguido, ${ }^{1}$ \\ Jessica González, ${ }^{1}$ Nuria López-Bigas, ${ }^{3,7}$ Pablo Menendez, ${ }^{6,7}$ \\ Elaine Dzierzak, ${ }^{2}$ Lluis Espinosa, ${ }^{1 *}$ and Anna Bigas ${ }^{1 *}$
}

1Program de Recerca en Càncer, Institut Hospital del Mar d'Investigacions Mèdiques, Parc de Recerca Biomèdica de Barcelona,
08003 Barcelona, Spain
2Erasmus MC Stem Cell and Regenerative Medicine Institute, Erasmus Medical Center, 3000 CA Rotterdam, Netherlands
3Research Unit on Biomedical Informatics, Department of Experimental and Health Sciences, Pompeu Fabra University,
08003 Barcelona, Spain
'Department of Genetic Engineering and Biotechnology, University of Dhaka, Dhaka 1000, Bangladesh
${ }^{5}$ Centre for Genomics and Oncological Research (Genyo), Pfizer-University of Granada-Andalusian Government,
18016 Granada, Spain
${ }^{6}$ José Carreras Leukaemia Research Institute, Cell Therapy Program, School of Medicine, University of Barcelona,
08036 Barcelona, Spain
7Institució Catalana de Recerca i Estudis Avançats (ICREA), 08010 Barcelona, Spain

Hematopoietic stem cell (HSC) specification occurs in the embryonic aorta and requires Notch activation; however, most of the Notch-regulated elements controlling de novo HSC generation are still unknown. Here, we identify putative direct Notch targets in the aorta-gonad-mesonephros (AGM) embryonic tissue by chromatin precipitation using antibodies against the Notch partner RBPj. By ChIP-on-chip analysis of the precipitated DNA, we identified 701 promoter regions that were candidates to be regulated by Notch in the AGM. One of the most enriched regions corresponded to the $C d c a 7$ gene, which was subsequently confirmed to recruit the RBPj factor but also Notch 1 in AGM cells. We found that during embryonic hematopoietic development, expression of $\mathrm{Cdca} 7$ is restricted to the hematopoietic clusters of the aorta, and it is strongly up-regulated in the hemogenic population during human embryonic stem cell hematopoietic differentiation in a Notchdependent manner. Down-regulation of Cdca7 mRNA in cultured AGM cells significantly induces hematopoietic differentiation and loss of the progenitor population. Finally, using loss-of-function experiments in zebrafish, we demonstrate that CDCA7 contributes to HSC emergence in vivo during embryonic development. Thus, our study identifies $\mathrm{Cdca} 7$ as an evolutionary conserved Notch target involved in HSC emergence.

\section{CORRESPONDENCE}

Anna Bigas:

abigas@imim.es

Abbreviations used: AGM, aorta-gonad-mesonephros; ChIP, chromatin immunoprecipitation; CHT, caudal hematopoietic tissue; EB, embryoid body; EMP, erythroid/myeloid progenitor; ESC, embryonic stem cell; HEP, hematoendothelial precursor; hpf, hour postfertilization; HSC, hematopoietic stem cell; ISH, in situ hybridization; $\mathrm{MO}$, morpholino oligo; SCF, stem cell factor; TSS, transcriptional start site.
Hematopoietic stem cells (HSCs) emerge from the major arterial vessels during embryonic development. Embryonic vascular development is closely associated with HSC generation because arteries provide the niche HSC generation and both lineages share a common endothelial progenitor (Zovein et al., 2008; Chen et al.,

\footnotetext{
*L. Espinosa and A. Bigas contributed equally to this paper. D.J.M. Bergen's present address is Cell Biology Laboratories, School of Biochemistry, University of Bristol, Bristol BS8 1TD, England, UK.

E. Dzierzak's present address is The Queen's Medical Research Institute, College of Medicine and Veterinary Medicine, The University of Edinburgh, Edinburgh EH16 4TJ, Scotland, UK.
}

2009). The process by which an HSC precursor with endothelial characteristic acquires the hematopoietic identity is known as endothelial to hematopoietic transition. HSCs develop within specific cell clusters budding from the endothelium to the lumen of the dorsal aorta in the region comprised between the junctions of the vitellin and umbilical arteries (Yokomizo and Dzierzak, 2010). These hematopoietic clusters

- 2014 Guiu et al. This article is distributed under the terms of an AttributionNoncommercial-Share Alike-No Mirror Sites license for the first six months Noncommercial-Share Alike-No Mirror Sites license for the first six months
after the publication date (see http://www.rupress.org/terms). After six months it is available under a Creative Commons License (Attribution-NoncommercialShare Alike 3.0 Unported license, as described at http://creativecommons.org/ licenses/by-nc-sa/3.0/). 
contain a variety of cells that express different cell surface markers such as c-kit or CD41 or CD45 and include those that will acquire the stemness capacity. After release into circulation, these cells are amplified in the fetal liver, giving rise to the adult HSCs.

The process of HSC generation requires the orchestration of crucial developmental pathways, including Notch and Wnt (Robert-Moreno et al., 2005; Ruiz-Herguido et al., 2012). Notch signaling regulates cell fate decisions with a central role in vascular and hematopoietic development (Bigas and Espinosa, 2012). Notch activity is first required to generate arteries, and Notch inhibition favors vein formation from the prepatterned endothelial network (You et al., 2005). Activation of Notch can be achieved by its interaction with either Delta or Jagged ligands, thus triggering the proteolytic cleavage and release of the active Notch intracellular fragment (ICN) that will induce a transcriptional response together with its nuclear partners RBPj and Mastermind (Mam). However, Notch activation during arterial determination specifically depends on the Delta4 ligand (Duarte et al., 2004; Krebs et al., 2004), whereas HSC generation in the hematopoietic clusters of the aortagonad-mesonephros (AGM) is mostly dependent on Jagged1 (Robert-Moreno et al., 2008). Thus, Jagged1-deficient embryos provide a unique system to study the role of Notch in embryonic hematopoiesis in a normal arterial scenario. This specific Notch function is not restricted to mammals, as it also regulates zebrafish (Burns et al., 2005) as well as Drosophila melanogaster hematopoietic development (Mandal et al., 2004; Terriente-Felix et al., 2013). In the mouse, only two direct Notch targets involved in HSC generation have been identified, but it is expected that other genes that participate in this process will also depend on Notch, as it has been shown in Drosophila (Terriente-Felix et al., 2013). In particular, Notch1 receptor signaling induces the activation of an incoherent feed-forward loop involving the Hairy and enhancer of split 1 (Hes1) repressor and the Gata2 transcription factor, which results in fine tuning of Gata2 levels and is essential to generate functional HSCs (Guiu et al., 2013). Similar regulatory loops for other Notch-dependent genes have been identified in Drosophila (Krejcí and Bray, 2007), which indicates the conservation of a mechanism that modulates context-specific targets through general Notch effectors such as Hes repressors. Genes regulated by these feed-forward regulatory loops are hard to identify in most of the screenings because once Notch is artificially stimulated or repressed, both the activating and the repressing complexes are simultaneously modified.

To identify novel HSC regulators that are targets of Notch in the AGM, we have based our strategy on (a) the identification of gene promoters that bind RBPj, (b) the selection of candidate genes by the presence of RBP binding consensus, and (c) the analysis of the expression patterns in the AGM of WT and Jag1 mutant embryos. Following this strategy, we identified Cell division cycle associated 7 (Cdca7) as a Notch/ RBPj target gene that is activated in the HSC precursors in the mouse embryo and maintained thereafter in distinct undifferentiated hematopoietic populations. Notch-dependent induction of $C d c a 7$ expression is recapitulated during early hematopoietic differentiation of human embryonic stem cells (ESCs [hESCs]), whereas down-regulation of Cdca 7 in the AGM cells induces a rapid differentiation of hematopoietic progenitors. In the zebrafish embryo, knocking down Cdca7 significantly reduced HSC generation in vivo.

\section{RESULTS}

\section{Screening for novel Notch/RBPj transcriptional targets in the AGM region}

We performed chromatin immunoprecipitation (ChIP)on-chip analysis with anti-RBPj antibodies using cross-linked chromatin from embryonic day (E) 11.5 dissected AGMs (scheme in Fig. 1 A). A set of putative targets was obtained with a stringent analysis by combining three bioinformatic tools (iChip1, iChip2, and Chipper; Fig. 1 B). Compared with the whole set of probes represented in the array (includes from -5 to $2.5 \mathrm{~kb}$ from the transcriptional start sites [TSSs]), $\mathrm{RBPj}$-bound regions showed enrichment in the proximal promoters, including the TSSs (Fig. $1 \mathrm{C}$ ). When overlapping the putative $\mathrm{RBPj} /$ Notch targets from the three independent analyses, 701 promoter regions showed enriched RBPj recruitment relative to the input, of which 676 (675 genes and 1 miRNA) were annotated with an Ensembl gene ID (Fig. 1 B and Table S1). Our list of RBP-binding genes included two $\mathrm{Hey} / \mathrm{Hes}$ family members, as well as other previously identified Notch targets such as Bcl-2, NRARP, PTEN, and Deltex2 (Table S1). Precipitation with an irrelevant Ig confirmed the specificity of the experiment (not depicted). In silico analysis of the promoter regions of identified genes showed a strong enrichment of RBPj motifs in the $-1-\mathrm{kb}$ region from their TSS sequence (Fig. $1 \mathrm{D}$ ). To investigate the possibility that Notch/RBPj-regulated genes in the AGM were clustered into specific functions or signaling pathways, Gene Ontology (GO) analysis (GO gene function and GO KEGG pathways) was performed. We found that genes identified as RBPj targets associated with DNA/chromatin regulation, cell division, and stem cell division. Remarkably, genes associated to the Wnt and Notch pathways were also significantly enriched in the group of RBPj targets (Fig. 1 E). By literature mining, we found that several of the identified genes played a recognized function in embryonic development, cancer, and/or hematopoiesis (Fig. $1 \mathrm{~F}$ ). These genes include the transcription factors SRY-related HMG-box-4 (Sox4) and homeobox A1 (HoxA1), the cell cycle regulator $\mathrm{Cdca}$, the Notch receptor modulator Ktelc1 (Rumi), the Delta ubiquitin ligase Mindbomb2 (Mib2), and the canonical Notch targets Hes 1 and Hey 1.

We further validated our ChIP-on-chip results by quantitative PCR (qPCR) analysis on an independent RBPj precipitation using primers around the enriched peaks of six randomly selected target genes. Analysis of the WAS protein family member 1 (Wasf1), Epithelial cell transforming sequences 2 oncogene (Ect2), Cdca7, Hes1, using the 28S ribosomal RNA $(R 28 S)$ as a negative control, confirmed the enrichment detected by ChIP-on-chip (Fig. $1 \mathrm{G}$ ). In contrast, the genes Fbx19, Gna12, and Gnai, which were also identified in the initial 
A

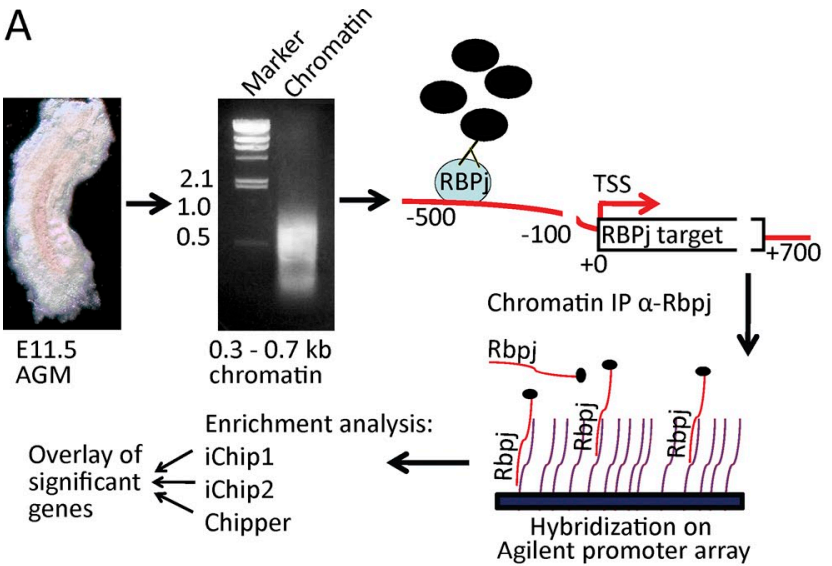

D Screening of RbpJ binding motifs present in $-1 \mathrm{~kb}$ to $+0.2 \mathrm{~kb}$ promoters

\begin{tabular}{lcccc}
\hline Group & RBP motif & no RBP motif & $\begin{array}{c}\text { Total scanned } \\
\text { promoters }\end{array}$ & $\begin{array}{c}\text { Ratio } \\
\text { (motif vs total) }\end{array}$ \\
\hline Putative target & $25^{*}$ & 650 & 675 & $1: 27$ \\
Non enriched genes & 374 & 15684 & 16058 & $1: 429$ \\
Total & 399 & 16334 & 13733 & $1: 41.9$
\end{tabular}

F Selection of targets with function during development or related with disease

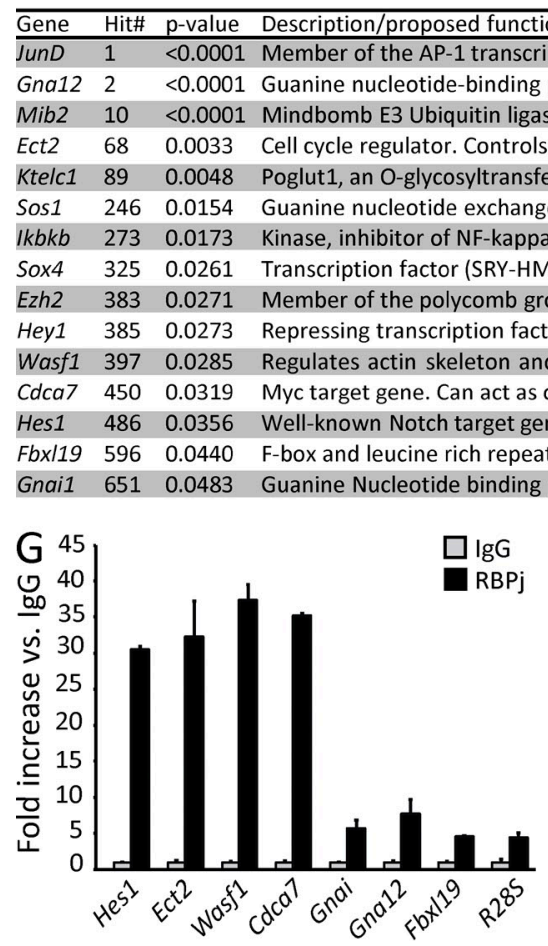

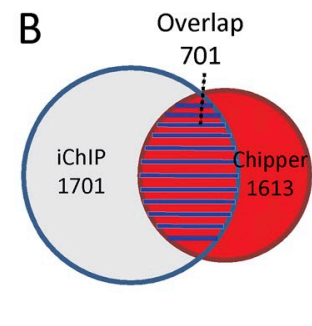

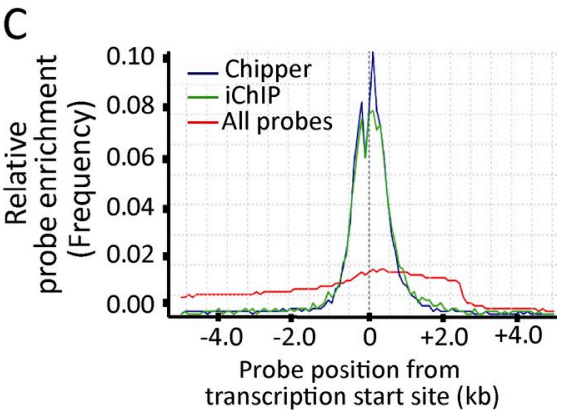

$\mathrm{E}$

Biological process

DNA dependent regulation of transcription (negative) Regulation of expression (negative)

Histone modification Induction of programmed cell death

Cell division

Positive regulation of apoptosis

Histone demethylation

Negative regulation of

DNA binding

I-kB kinase/NF-кB

cascade

Stem cell division
Associated pathway

Cell cycle

P53 signaling pathway

Wnt signaling pathway

Adherens junctions

Notch signaling pathway

Apoptosis

Focal adhesion

FDR $p$-value scale

\begin{tabular}{lll}
0 & 0.05 & 1.0 \\
\hline
\end{tabular}

Significant/ non-significant

Figure 1. ChIP-on-chip analysis of E11.5 AGMs. (A) Schematic representation of the ChIP-on-chip procedure. (B) 701 overlapping promoter regions (red with blue stripes) between iChip (blue circle) and Chipper (red circle) software were identified. (C) Comparing the relative probe enrichment of identified RBPj targets by Chipper and iChip to all probes. (D) RBPj-binding motif scanning (TGGGAAANT) in a range of -1 to $2 \mathrm{~kb}$ from the TSS showed significantly more binding sites in the 675 promoter regions with an Ensembl ID than all of the promoter regions $\left({ }^{*}, P=0.021 ; \chi^{2}=5.259\right)$. (E) GO biological process (GO-BP) and pathway (KEGG) analysis in the 676 overlapping group. (F) Selection of putative RBPj targets showing the gene symbol, hit number, and enrichment p-value. (G) qPCR analysis for RBPj recruitment to the selected genes in an independent ChIP from E11.5 AGMs $(n=3)$. (H) Recruitment of ICN 1 to the selected genes, assessed by ChIP from E11.5 AGMs $(n=3)$. (I) qRT-PCR analysis on cDNA of E10.5 dissected AGMs from Jag $1^{+/+}$and Jag 1-/- embryos from confirmed ICN1 and RBPj target genes (Ect2, Wasf1, and Hes 1); Gata2 and DII4 are shown as controls $(n=4)$. (J) A pool of six E10.5 AGMs from Jag $1^{-/-}$was disrupted with collagenase and cultured. In this culture ICN1-IRES-GFP was transduced, and after 1 wk, infected cells (GFP+) were sorted and the indicated genes were analyzed by qRT-PCR $(n=3)$. Error bars represent the SD. 
screening, showed very poor enrichment ratios and were therefore considered as false positives (Fig. 1 G). Because RBPj recruitment is not exclusive of genes that contain active Notch, we analyzed whether the truncated intracellular Notch1 (ICN1) was also recruited to these promoters in the AGM of E11.5 embryos. ChIP assay using specific antibodies showed that four validated RBPj target promoters (Wasf1, Ect2, Cdca7, and hes1) also recruited active Notch1 (Fig. $1 \mathrm{H}$ ), supporting the notion that Notch1 regulates their expression at the time of HSC emergence.

\section{Novel identified Notch/RBPj targets are Jagged1/Notch1-dependent genes}

Because HSC generation is highly dependent on the Notch ligand Jag1 (Robert-Moreno et al., 2008), we focused on the identification of Notch/ $\mathrm{RBPj}$ targets that are misregulated in a Jag1-deficient background. We obtained RNA from E10.5 AGMs of Jag1 ${ }^{+/+}$and Jag1-/- embryos and performed expression analysis of our candidate genes. All selected Notch targets were down-regulated in the absence of Jag1, in contrast to the Notch ligand D1l4 which was up-regulated in this specific mutant (Fig. 1 I). The Notch target Gata2 was also down-regulated in the Jag1-deficient AGM as shown previously (Robert-Moreno et al., 2008). Conversely, transduction of AGM cells from Jag1 ${ }^{-/-}$embryos with active ICN1 resulted in the up-regulation of all selected targets (from 2- to 16-fold) compared with the control (Fig. $1 \mathrm{~J}$ ).

Analysis of the sequence comprising $10 \mathrm{~kb}$ of the $5^{\prime}$ regulatory regions using the Genomatix software demonstrated that putative $\mathrm{RBPj}$-binding sites were present in the proximal promoter of all of the identified targets. Head-to-head dimerization of the Notch factor recruited to closely localized $\mathrm{RBPj}$ binding sites (15-17 bp from core to core) is important for transcriptional regulation of specific genes such as Hes1 (Fig. S1; Arnett et al., 2010). Interestingly, we found that the Cdca7 promoter contained three putative $\mathrm{RBPj}$-binding sites in the region comprised between the $-5 \mathrm{~kb}$ and the TSS, and it contained two adjacent $\mathrm{RBPj}$ sites separated by a distance of $43 \mathrm{bp}$ that mapped close to the TSS. This regulatory region was covered by the Chip-on-chip probes and was highly enriched in the RBPj precipitation (Fig. $2 \mathrm{~A}$ ).

Cdca7 transcriptional activation depends on Notch signaling We further validated the $\mathrm{RBPj}$ recruitment to $C d c a 7$ using primers covering the different regions of the locus (Fig. $2 \mathrm{~B}$ ). We confirmed that the region containing the two adjacent RBPj-binding sites ( -260 and -217 bp) was highly enriched in the $\mathrm{RBPj}$ precipitates when normalized for the control IgG precipitation ( $\sim 206$-fold) or when compared with other regions including putative binding sites $(-4,087,-7,882$, and $-9,004$ bp) in the Cdca 7 gene (Fig. 2 B). Importantly, Notch1 and its coactivator Mam were also specifically recruited to the same region of the Cdca 7 promoter (Fig. 2, C and D). To study whether Notch regulated Cdca 7 transcription, we cloned the region comprised between -511 and $50 \mathrm{bp}$ of the gene on a luciferase reporter vector and tested its response to Notch activation or inactivation in HEK-293T cells. Simultaneous expression of the ICN1 construct $(\mathrm{N} 1 \Delta \mathrm{E})$ and Mam significantly increased the activity of the $C d c a 7$ promoter compared with the control or with ICN1 construct alone (Fig. 2 E). Conversely, inhibition of Notch activity by DAPT or by transfection of a dominant-negative form of $\mathrm{RBPj}$ resulted in a significant reduction in the activity of the promoter (Fig. $2 \mathrm{E}$ ). Furthermore, we found that mutation of both adjacent RBPbinding sites totally abolished the Notch-dependent activation of the construct (Fig. 2 F), whereas single mutations of the distal site $(-260)$ did not significantly affect its activity. Altogether, these results indicate that a Notch complex containing $\mathrm{RBPj}$, Notch1, and Mam directly regulates the transcriptional activation of Cdca7. However, in vitro activation of the proximal promoter does not require Notch homodimerization.

\section{Cdca7 is expressed in the aortic clusters and hemogenic precursors from AGM and hESCs}

We next investigated the putative role of CDCA7 during development of the murine hematopoietic system. By in situ hybridization (ISH) of midgestation embryos, we found that Cdca 7 was mainly expressed in the hematopoietic cluster-like structures in the AGM, which contain the newly formed HSCs, but also in the fetal liver (Fig. 3 A). In contrast, Cdca 7 was not detected in the rest of the aortic endothelial cells, suggesting that $\mathrm{Cdca} 7$ is involved in hematopoietic emergence but not in arterial specification (Fig. 3 A). Similar results were obtained by immunostaining of the CDCA7 protein (Fig. 3 B). As expected, ISH analysis showed that $\mathrm{Cdca} 7$ expression was completely abolished in the aorta of Jag $1^{-/-}$embryos (Fig. 3 C), in agreement with the qRT-PCR results (Fig. $1 \mathrm{I}$ ).

To study whether Cdca 7 is differentially expressed in specific HSC populations, we took advantage of gene expression data available in public databases (GEO accession nos. GSE37000 and GSE27787). These experiments include data of purified HSCs obtained from E11.5 AGM $\left(\mathrm{VEC}^{+} \mathrm{CD} 45^{+}\right)$, E12.5 FL (LSK), and LT-HSCs from adult BM (CD150 ${ }^{+} \mathrm{CD} 48^{-} \mathrm{LSK}$; McKinney-Freeman et al., 2012) and different subpopulations of hematopoietic progenitors and mature cells (Konuma et al., 2011). Interestingly, Cdca 7 mRNA is highly expressed in HSCs from all different developmental stages (Fig. 3 D), and its expression is lower in differentiated cells from specific hematopoietic lineages (Fig. 3 E). To directly determine the expression levels of $\mathrm{Cdca} 7$ in different hematopoietic subpopulations of the AGM clusters at E10.5, we obtained mRNA from cells sorted using specific markers for pure endothelial $\left(\mathrm{CD} 31^{+} \mathrm{cKit}^{-} \mathrm{CD} 41^{-} \mathrm{CD} 45^{-}\right)$, hemogenic endothelial $\left(\mathrm{CD} 31^{+} \mathrm{CKit}^{-} \mathrm{CD} 41^{+} \mathrm{CD} 45^{-}\right)$, prehematopoietic $\left(\mathrm{CD} 31^{+} \mathrm{cKit}{ }^{+} \mathrm{CD} 41^{+} \mathrm{CD} 45^{-}\right)$, and hematopoietic cluster cells $\left(\mathrm{CD} 31^{+} \mathrm{CKit}^{+} \mathrm{CD} 41^{+} \mathrm{CD} 45^{+}\right) . \mathrm{Cdca} 7$ was up-regulated in the sorted $\mathrm{cKit}^{+}$cells, when compared with the $\mathrm{cKit}^{-}$, with $\sim 5$ $\log _{2}$-fold difference (Fig. S2 A). The highest Cdca 7 levels were detected in the $\mathrm{CD} 31^{+} \mathrm{CD} 41^{+} \mathrm{CKit}{ }^{+} \mathrm{CD} 45^{-}$population (Fig. $3 \mathrm{~F}$ ), which contains the putative precursors of the HSCs. To a lesser extent, Cdca 7 was also present in the population that contains the functional HSCs and hematopoietic progenitors 

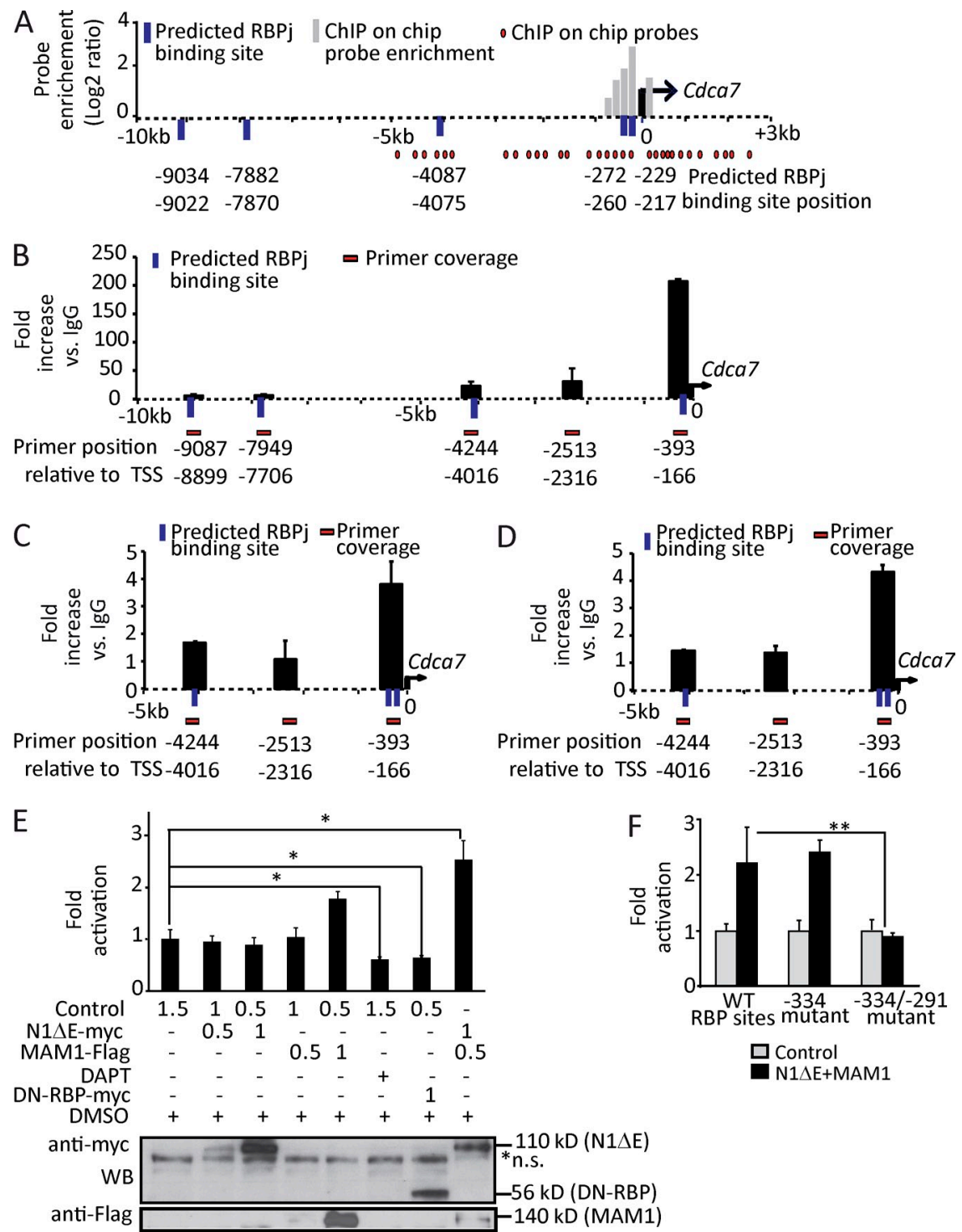

Figure 2. Cdca7 is a direct Notch target gene through two predicted RBPj-binding sites. (A) Schematic representation of the promoter region of $\mathrm{Cdca} 7$ showing the array probe position (red circles), DNA (black dashed line), TSS (black arrow), putative RBPj-binding site (blue bars), and probe enrichment in $\log _{2}$ ratio (gray bars). RBPj-binding sites were identified with the STORM and Genomatix software scanning from the -10 - to $0-\mathrm{kb}$ region of each target gene. (B) ChIP with anti-RBPj. (C) ChIP with anti-N1IC. (D) ChIP with anti-MAM1. In B-D, chromatin was extracted from E10.5 dissected AGMs $(n=2)$. (E and F) Luciferase activity from Cdca7 promoter ( $-511 / 50$ bp) WT (E) and mutant RBP sites (F) in the presence of the specified transfected plasmids into HEK-293T cells (micrograms of transfected plasmid are indicated; $n=3$ ). In the bottom panels, Western blot of the transfected proteins is shown. Error bars represent the SD. Significant differences are indicated by asterisks (*, $\left.\mathrm{P}<0.05 ;{ }^{* *}, \mathrm{P}<0.01\right)$.
$\left(\mathrm{CD} 31^{+} \mathrm{CD}_{4}{ }^{+} \mathrm{CKit}^{+} \mathrm{CD} 45^{+}\right)$and maintained in the LSK population isolated from adult BM (Fig. $3 \mathrm{~F}$ ). Based on all of this data, we proposed that CDCA7 may play a role during endothelial to hematopoietic transition in the human embryo (Ivanovs et al., 2011). We took advantage of the hematoendothelial differentiation system using the hESC lines H9 and AND1 and two hematopoietic differentiation strategies: embryoid bodies (EBs; Fig. S2 B) and OP9 co-culture system (Fig. 3 G; Wang et al., 2004; Real et al., 2012; Bueno et al., 2013). In both conditions, we observed the appearance of hematoendothelial precursors (HEPs; $\mathrm{CD} 31^{+} \mathrm{CD} 34^{+} \mathrm{CD} 45^{-}$), followed by the generation of hematopoietic cells $\left(\mathrm{CD} 45^{+}\right)$. We sorted these subpopulations, obtained mRNA, and measured the expression levels of human CDCA7 variant 2, which is homologous to the murine $C d c a 7$ (Fig. S2 C). We found that CDCA7 mRNA was strongly enriched in the human HEPs obtained from both EB and OP9 differentiation systems, confirming the trend observed in the murine AGM cells (Fig. S2 D and Fig. $3 \mathrm{H}$ ). To test whether CDCA7 expression during hematopoietic differentiation of hESC was dependent on Notch activity, which is known to modulate hematopoietic differentiation of ESCs (Yu et al., 2008; Lee et al., 2013; Rafii et al., 2013), we included Notch/ $\gamma$-secretase inhibitor (CompE) in our experiments. We found that compE treatment significantly reduced the levels of CDCA7 expression in both the HEP and the CD $45^{+}$populations (Fig. 3 I). Further supporting a role for CDCA7 downstream of Notch in the human hematopoietic system, we found that Notch1 is recruited to the region spanning $400 \mathrm{bp}$ to the $5^{\prime}$ region of CDCA7 in human peripheral blood CD $34^{+}$cells (Lin, M.I., and L. Zon, personal communication).

\section{Cdca7 maintains the undifferentiated phenotype of the hematopoietic lineage}

To directly test the functional requirement of CDCA7 during mouse embryonic hematopoiesis, we obtained E10.5 AGM 
A $\quad \mathrm{ISH} C \mathrm{Cdca} 7$
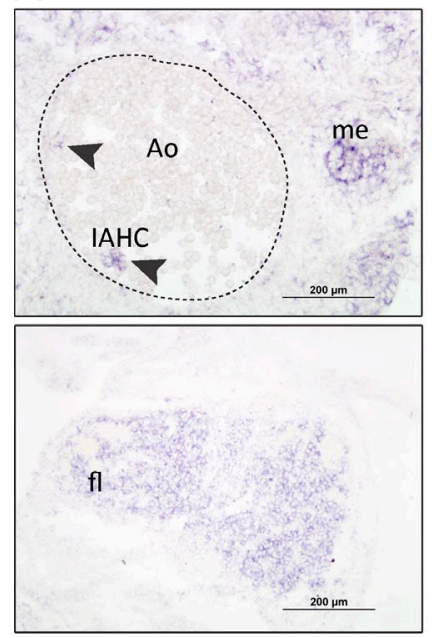

D 1000
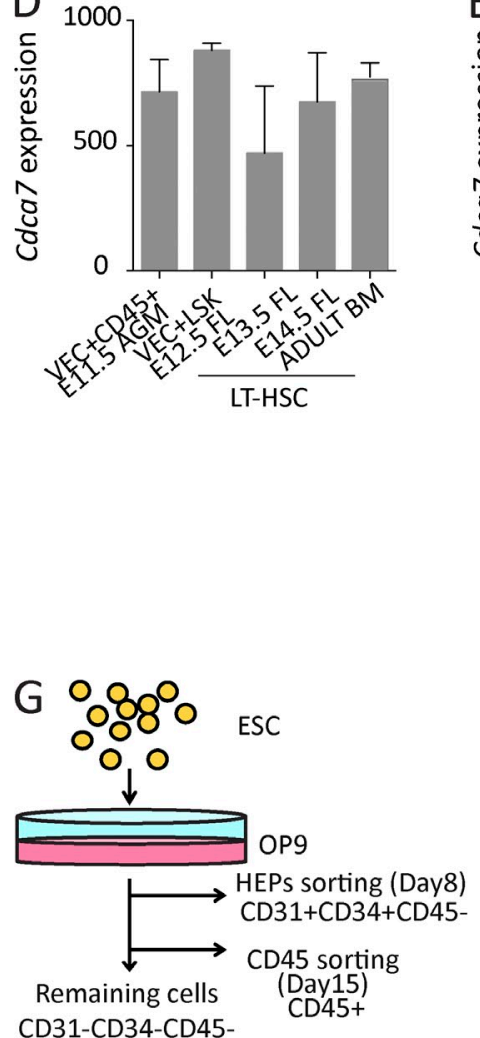

B DAPI/CDCA7
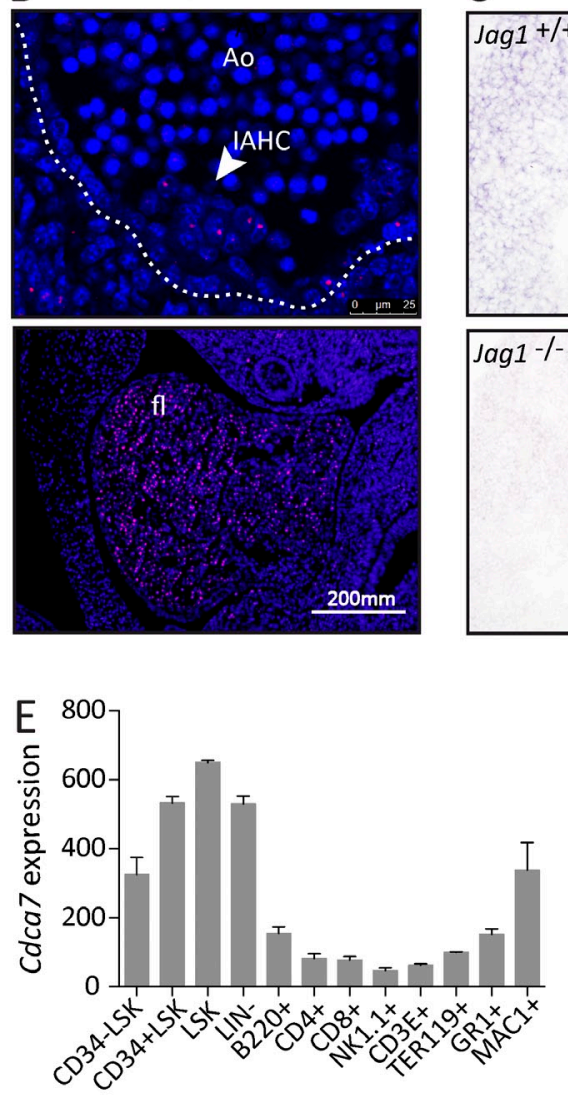

C
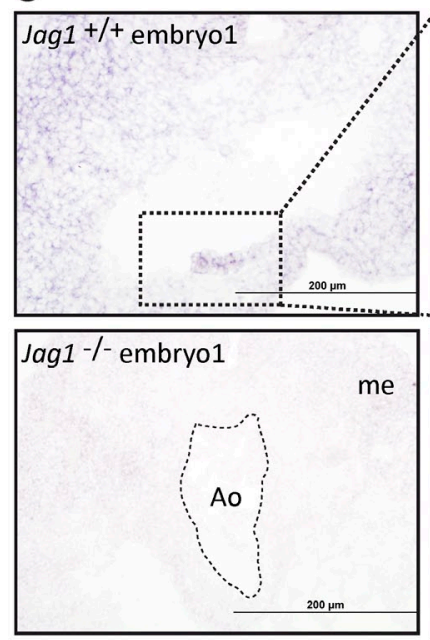

F Aorta E10.5
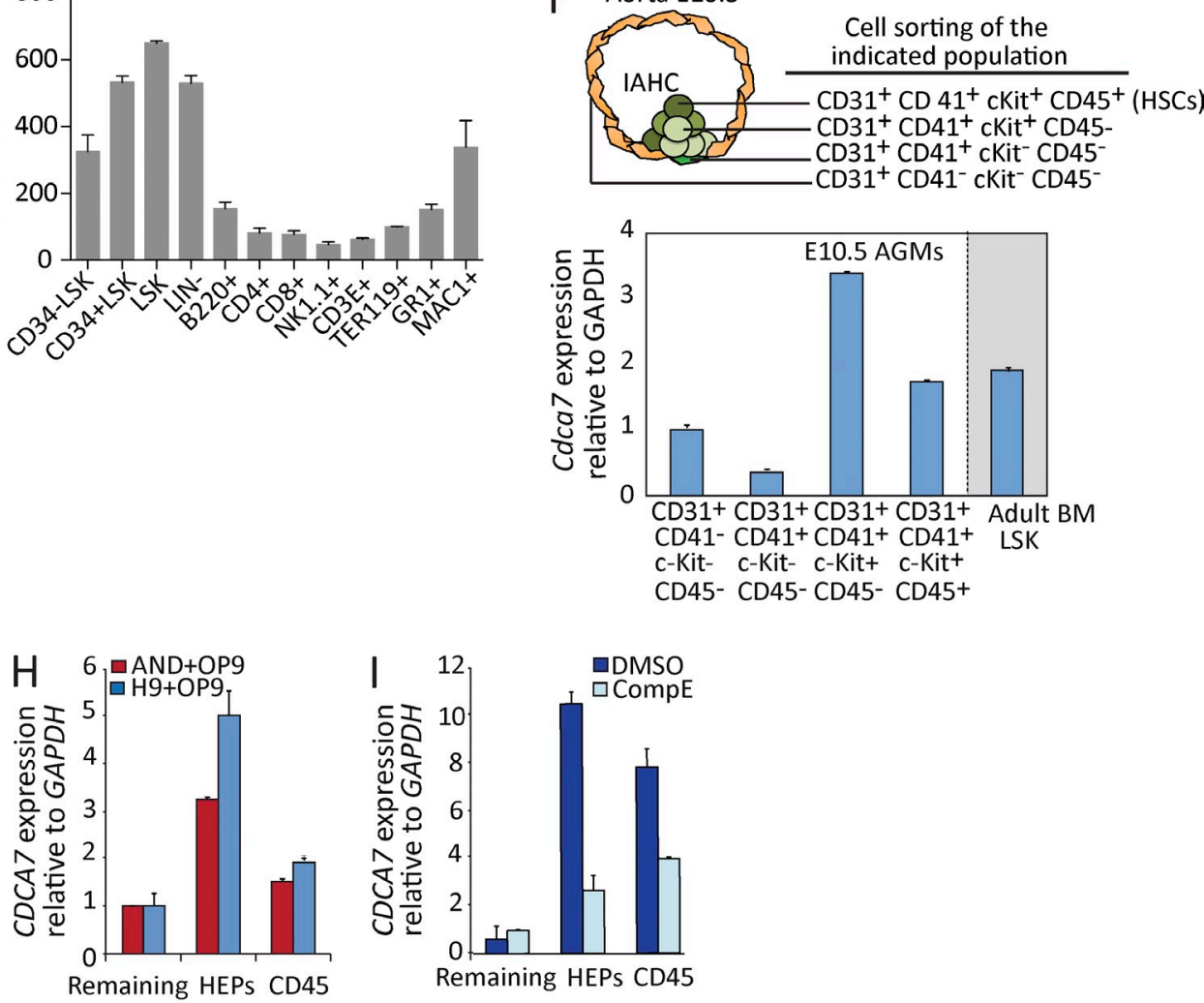

Figure 3. Cdca7 is expressed in mouse and human embryonic hematopoietic progenitor cells. (A) ISH of Cdca7 on E10.5 embryos. Arrowheads indicate hematopoietic clusters in the top panel. Fetal liver (fl) staining is shown in the bottom panel. (B) E11.5 embryo immunofluorescence is shown. (C) ISH comparing E10.5 Jag $1^{+/+}$with Jag $1^{-/-}$embryos. Dashed lines indicate the aortic endothelium and bars indicate the scale. Ao, aorta in the AGM region; IAHC, intraaortic hematopoietic cluster; me, mesonephros. (D-F) Cdca7 expression from the indicated purified populations from the embryo to the adult. ( $D$ and $E$ ) Gene expression from purified HSCs obtained from E11.5 AGM (VEC+CD45+), E12.5 FL (LSK), and LT-HSCs from adult BM $\left(\mathrm{CD} 150^{+} \mathrm{CD} 48^{-} \mathrm{LSK}\right)$ and different subpopulations of hematopoietic progenitors and mature cells. Data are derived from public databases. (F) Cdca7 expression on purified E10.5 AGM subpopulations and adult BM LSK. (G) Experimental design of hESC hematopoietic differentiation on OP9. (H and I) HEPs $\left(C D 31^{+} \mathrm{CD} 34^{+} \mathrm{CD} 45^{-}\right)$and $\mathrm{CD} 45^{+}$hematopoietic differentiated cells were sorted and analyzed by qRT-PCR relative to nonhematopoietic remaining cells $\left(\mathrm{CD} 31^{-} \mathrm{CD} 34^{-} \mathrm{CD} 45^{-}\right)$. Cdca7 expression was determined by qPCR $(n=3)$. Error bars represent the SD. 


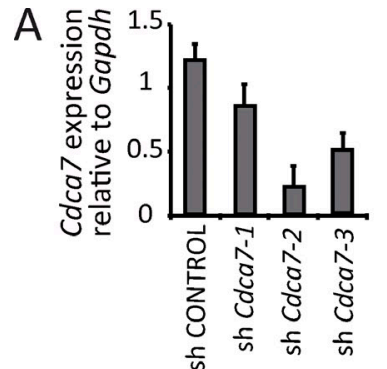

WB:

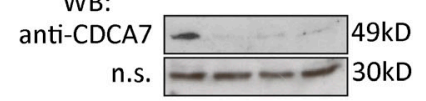

B

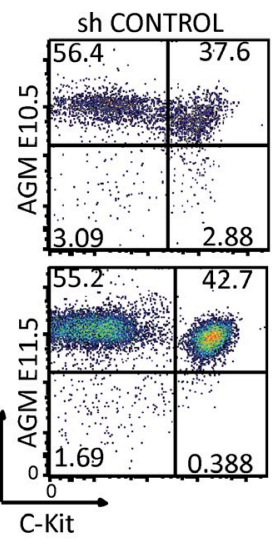

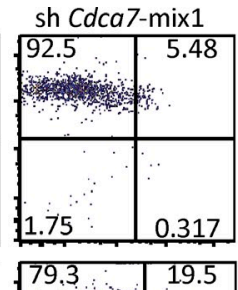

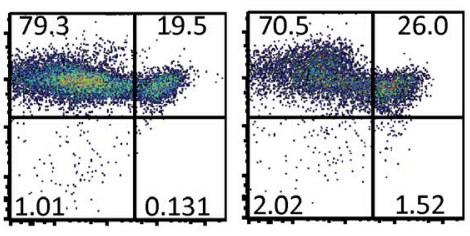

\begin{tabular}{lll}
2.02 & 1.52 \\
\hline
\end{tabular}
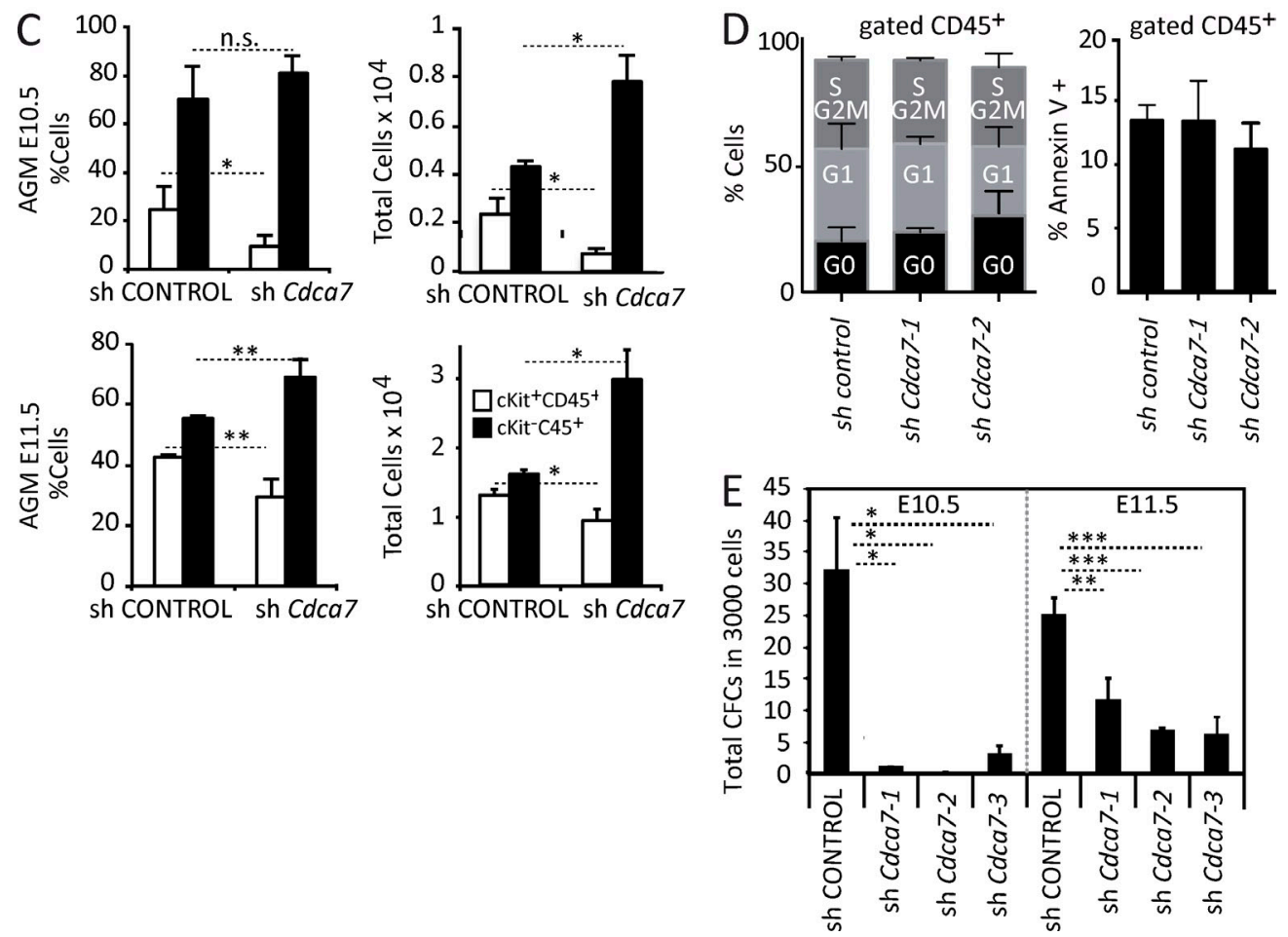

Figure 4. CDCA7 is required to maintain embryonic hematopoietic progenitors. (A) shCdca7-1, shCdca7-2, and shCdca7-3 were tested in 32D myeloid progenitor cell line by qPCR (top) and Western blot (bottom); an unspecific band was used as a loading control. (B) E10.5 and E11.5 AGM cells were cultured and transduced with the same infective viral particles of shControl and shCdca7 (mix 1: shCdca7-1 + shCdca7-2; mix 2: shCdca7-1 + shCdca7-3). After 1 wk, the cells were analyzed by flow cytometry (CD45+ ${ }^{+} K_{i t}+$ : hematopoietic progenitors; $\mathrm{CD}_{4} 5^{+} \mathrm{cKit}^{-}$: differentiated hematopoietic cells). One representative experiment is shown. (C) Mean of three independent experiments is plotted. (D) Cell cycle profile and apoptosis was determined in cells after 1 wk of culture. Graphs represent mean percentage of cells in each phase (left) and percentage of cells with Annexin V staining (right) from two independent experiments. No statistically significant differences were found. (E) After 1 wk in the hematopoietic culture, 3,000 cells were plated in a CFC culture. Bars represent the mean and SD of CFCs obtained from three independent cultures. Significant differences are indicated by asterisks $\left({ }^{*}, \mathrm{P}<0.05\right.$; $\left.{ }^{* *}, P<0.01 ;{ }^{* *}, P<0.001\right)$.

cells and transduced them with lentiviral vectors containing shRNA targeting Cdca7 or the scrambled control (Fig. 4 A). Control cells or Cdca 7 knocked down cells were cultured for $7 \mathrm{~d}$ in the presence of cytokines and analyzed by flow cytometry for the presence of $\mathrm{CD} 45^{+}$and $\mathrm{cKit}^{+}$cells. In the control cultures, we obtained a mean of $30 \%$ of $\mathrm{CD} 45^{+} \mathrm{cKit}^{+}$doublepositive hematopoietic progenitors that was reduced by eightfold after Cdca 7 knockdown. In contrast, these cultures showed a forced differentiation into more mature $\mathrm{CD} 45^{+} \mathrm{cKit}^{-}$cells. Similar results were obtained from E11.5 AGM cultures (Fig. 4 B). Reduction in the hematopoietic progenitors was also detected when total cell numbers were analyzed (Fig. 4 C). However, total cell number after culture was similar in both conditions, and we did not detect any significant effect on the cell cycle profile or the apoptotic rate in the Cdca7-depleted hematopoietic cells (Fig. 4 D). These results strongly suggest 

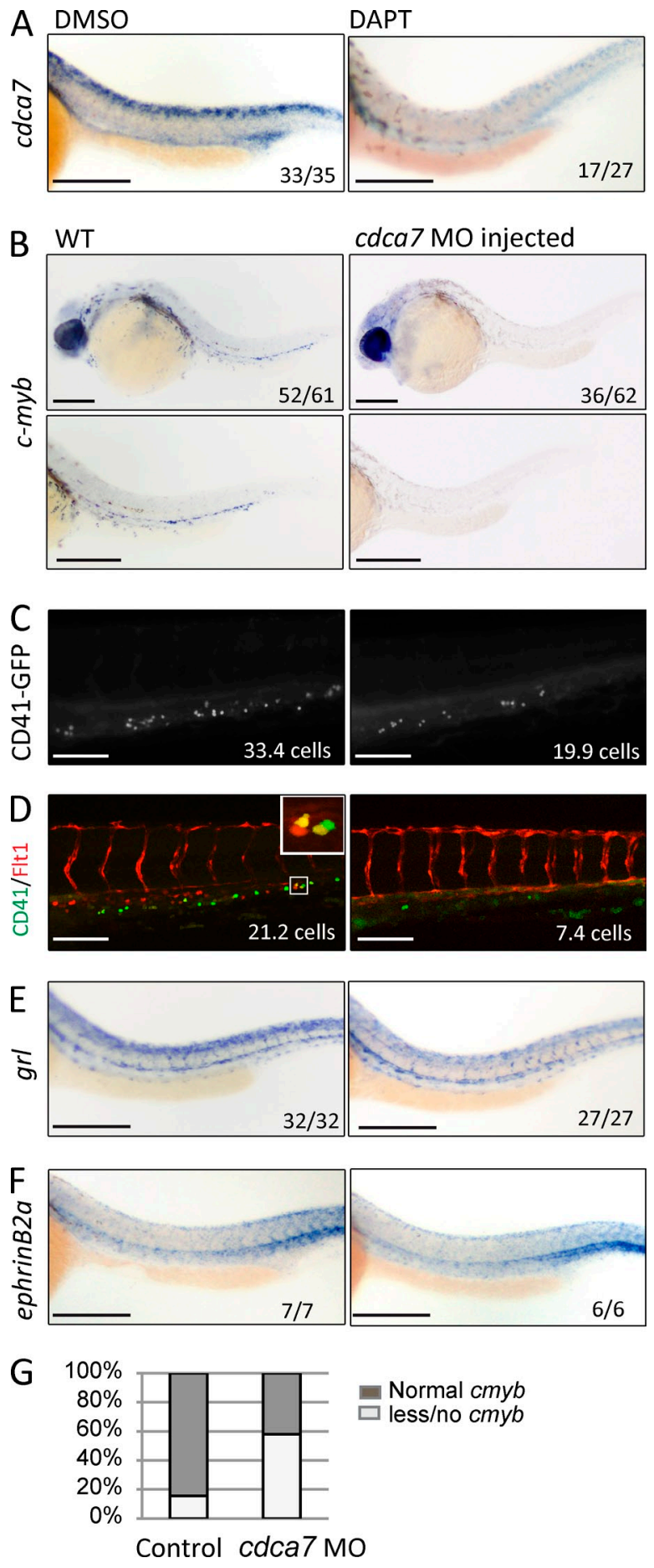

Figure 5. HSC formation is impaired in cdca 7 morphants. (A) cdca7 ISH of representative embryos treated at $6 \mathrm{hpf}$ for $24 \mathrm{~h}$ with DMSO or $100 \mu$ M DAPT. (B) Representative embryos (top) and detailed images of AGM region (bottom) from embryos treated with control or cdca7 MOs. Hematopoietic cells were detected by cmyb ISH at $30 \mathrm{hpf}$ or by CD41-GFP at $50 \mathrm{hpf}(\mathrm{C})$. The number of CD41-GFP-positive cells is significantly reduced upon cdca7 $\mathrm{MO}$ injection ( $P=0.01)$. (D) Representative images from CD41-GFP and Flt1-RFP embryos treated with control or cdca7 MOs. Number of double-positive cells is indicated. A detail of CD41-GFP+/FIt1-RFP+ HSCs is depicted in the inset. ( $E$ and F) The dorsal aorta integrity is that CDCA7 regulates hematopoietic emergence and differentiation rather than survival or proliferation of existing hematopoietic cells. Furthermore, knocking down Cdca 7 in AGM cells totally abolished (in E10.5 cells) or strongly reduced (in E11.5 cells) their capacity to generate lineage-specific colonic (CFCs; Fig. 4 E). These results indicate that CDCA7 has a dominant role in maintaining the undifferentiated phenotype of the newly formed HSCs and progenitors.

\section{Cdca7 is required for in vivo definitive hematopoietic development in zebrafish}

We first confirmed the expression pattern of $c d c a 7$ in the zebrafish embryos by ISH and found expression in the aorta of 94.3\% of WT embryos (DMSO-treated control), whereas in vivo treatment with the Notch $/ \gamma$-secretase inhibitor DAPT led to a severe reduction of $c d c a 7$ levels in $63 \%$ of treated embryos $(n=2,33 / 35$ DMSO vs. $10 / 27$ DAPT showing normal cdca7 levels; Fig. 5 A; Thisse et al., 2001). These results indicate that $c d c a 7$ expression is also downstream of Notch in this system.

Next, we tested the requirement of $c d c a 7$ during the HSC generation process in zebrafish. We took advantage of antisense $c d c a 7$ morpholino oligos (MOs) that had been previously tested (Ma et al., 2012; 2.3-fold reduction detected by qRT-PCR [not depicted]). By ISH, we detected $c m y b$ expression (specifically labeling definitive HSCs and progenitors) in $84.4 \%$ of WT embryos compared with $41.9 \%$ of the embryos injected with cdca 7 MOs $(n=3,77$ control embryos and 62 morphants analyzed; Fig. 5, B and G). Similar results were obtained with a second ATG MO against cdca 7 (57.1\% of treated embryos showed $c m y b$ expression; not depicted). Moreover, the reduction in runx 1 expression as detected by ISH indicated that $c d c a 7$ was required for specification of hemogenic endothelium (7/14 untreated embryos showed runx1 expression compared with $1 / 8$ in the $c d c a 7 \mathrm{MO}$-injected ones [not depicted]). Similarly, cdca $7 \mathrm{MO}$ treatment led to a reduction in the number of GFP-positive hematopoietic cells in the CD41-GFP line (Lin et al., 2005; $33.7 \pm 3.6$ in the untreated compared with $19.9 \pm 3.0$ cells in the MO-treated, $\mathrm{P}=0.009 ; n=1,13$, and 14 embryos, respectively; Fig. $5 \mathrm{C}$ ). The fact that CD41-GFP marks both HSCs and erythroid/ myeloid progenitors (EMPs), with EMPs being independent of Notch signaling (Bertrand et al., 2010), is in agreement with the observation that the number of CD41-GFP-positive cells was only reduced by $33 \%$ in the MO-treated embryos. EMPs have a posterior blood island/venous origin (Lawson and Weinstein, 2002), whereas HSCs have an arterial AGM origin (Warga et al., 2009). Consequently, detection of Flt1RFP, which is exclusively expressed in arterial cells (Bussmann

revealed by gridlock (hey2) and EphrinB2a expression in both WT and $c d c a 7 \mathrm{MO}$-injected embryos. The numbers in the panels indicate the number of embryos of the total pool that displayed phenotype or the number of positive cells. $(G)$ The percentages of cmyb expression are indicated in the graph. Bars: (A, B, E, and F) $200 \mu \mathrm{m}$; ( and D) $100 \mu \mathrm{m}$. 
et al., 2010), together with CD41 can distinguish between EMPs and HSCs (because RFP is very stable and HSCs remain RFP positive in the caudal hematopoietic tissue [CHT; Bertrand et al., 2008]). Quantification of the number of HSCs

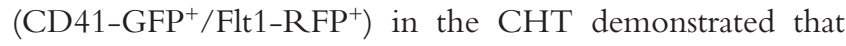
control embryos contain $21.2 \pm 3.3 \mathrm{GFP}^{+} / \mathrm{RFP}^{+}$compared with $7.4 \pm 3.1$ cells in the $c d c a 7 \mathrm{MO}$-injected embryos (data from one experiment; six and nine embryos analyzed, respectively; $\mathrm{P}=0.01$; Fig. $5 \mathrm{D}$ ). Supporting the notion that $c d c a 7$ knockdown does not affect arterial development, we did not detect any significant alteration in the expression levels of the arterial genes gridlock and EphrinB2a by ISH and expression of $\mathrm{Tg}(\mathrm{Flt1}$-RFP) in our MO-treated embryos (Fig. 5, D-F). Together, our results demonstrate that CDCA7 is downstream of Notch/RBPj and contributes to the emergence of HSCs and maintenance of hematopoietic progenitors during embryonic development.

\section{DISCUSSION}

Our genome-wide analysis of RBPj-targeted genes during embryonic hematopoietic development provides a source of candidates to function as Notch mediators during HSC specification. Because it is still under debate which is the embryonic population of cells that requires Notch activity to give rise to HSCs, we have used pools of dissected AGMs from E11.5 embryos to search for RBPj-binding promoters. To further define the best candidate genes for Notch-dependent regulation in the AGM, we have focused on those that contain conserved adjacent RBPj-binding sites (Arnett et al., 2010) and showed Notch1 recruitment in their promoters. Furthermore, because Jag1-deficient embryos display specific hematopoietic defects (Robert-Moreno et al., 2008), we have selected genes whose expression depends on Jag1 in the AGM. In this work, we have focused on the Cdca 7 gene, which scored positive to all of the aforementioned criteria, as a new Notch target gene involved in early hematopoietic development. In fact, we found that CDCA7 is required for the HSC and hematopoietic progenitor emergence in the zebrafish embryo.

Understanding the cellular and molecular mechanisms involved in HSC development is crucial for multiple therapeutic applications such as generation of HSCs from ESCs or induced pluripotent stem cells. This includes deciphering how endothelial-like cells acquire the hematopoietic fate and how a very restricted population achieves the stemness characteristics (LT-HSC; Taoudi et al., 2008) instead of just going through the hematopoietic pathway. We and others have previously shown that extra-embryonic yolk sac and embryonic stem-derived hematopoiesis do not require Notch activity (Schroeder et al., 2003; Robert-Moreno et al., 2007; Real et al., 2012), whereas it is essential to obtain transplantable definitive HSCs (Kumano et al., 2003). Here we found that Cdca7 is induced in a Notch-dependent manner during the initial stages of ESC differentiation into the hematopoietic lineage, but its expression is not maintained in the $\mathrm{CD} 45^{+}$mature population. Our results strongly suggest that sustained Notch signal and $C d c a 7$ expression contribute to prevent maturation of hematopoietic progenitor/stem cells. In agreement with this possibility, we found that down-regulation of Cdca7 in AGM cells results in forced differentiation of the $\mathrm{cKit}^{+}$progenitor population. In the ESC differentiation system, CDCA7 is temporarily activated in the $\mathrm{CD} 34^{+} \mathrm{CD} 45^{-}$HEPs but reduced in the $\mathrm{CD} 45^{+}$population, which could partially contribute to the engraftment inability of ESC-derived hematopoietic cells.

Cdca 7 was previously identified as a downstream target of Myc and E2F transcription factors (Haggerty et al., 2003; Goto et al., 2006). CDCA7 can also interact with Myc in the nucleus and participate in Myc-dependent transformation events. It is proposed that CDCA7 participates in cell cycle progression, which may be relevant for its involvement in oncogenic processes (Whitfield et al., 2002). In this sense, $C D C A 7$ is overexpressed in a variety of hematological tumors, predominantly in chronic myelogenous leukemia, but it has limited cell-transforming capacity both in vivo and in vitro (Osthus et al., 2005). However, we have not found any effect of CDCA7 on proliferation, nor cell death, in AGM hematopoietic cultures or in zebrafish hematopoietic cells (unpublished data). The precise physiological and biochemical function of CDCA7 remains obscure and requires further investigation. Here we show that $C d c a 7$ is expressed in different HSC and progenitor subpopulations, including the LTHSCs, and it is important for maintaining the undifferentiated phenotype. Moreover, our study shows that $\mathrm{Cdca} 7$ is downstream of Notch in hematopoietic cells in zebrafish, mouse, and human, indicating the high conservation of the Notch/ $\mathrm{RBPj} / \mathrm{CDCA} 7$ axis in hematopoietic development (CiauUitz et al., 2014). Interestingly, Cdca7 expression was also enriched in the lgr $5^{+}$intestinal stem cells (van der Flier et al., 2009), suggesting a more general stemness-related function.

\section{MATERIALS AND METHODS}

Animals. CD1, C57B6/J WT, and Jagged 1-/- (Xue et al., 1999) strains were used. Animals were housed under pathogen-free conditions, and all procedures were approved by the Animal Care Committee of Parc de Recerca Biomèdica de Barcelona and Generalitat de Catalunya. Embryos were obtained from timed pregnant females and staged by somite counting: E10.5 (31-40 sp), E11.5 (43-48). The detection of the vaginal plug was designated as day 0.5 . Mice and embryos were genotyped by PCR.

qRT-PCR. Total RNA was extracted with a QIAGEN kit, and the RTFirst Strand cDNA Synthesis kit (GE Healthcare) was used to produce cDNA. qRT-PCR was performed in the LightCycler480 system using SYBR Green I Master kit (Roche). Primers used are shown in Tables S2 and S3.

Promoter analysis and luciferase assays. $C d c a 7$ promoter was analyzed using Genomatix software. For luciferase assays, $\mathrm{Cdca} 7$ was generated cloning the region from -511 to $50 \mathrm{bp}$ of Cdca 7 TSS into the pGL3 vector (primers: forward, 5'-TGCTAGATAAGAGGTGCTATGCTC-3'; and reverse, 5'-GTGCTAGCACCCACCAACC-3') and verified by sequencing. Two nucleotide (CC>AA) mutations were introduced by PCR at the -260 site alone or at both -260 and -217 core sites in the $C d c a 7$ reporter. Luciferase reporter assays were performed in HEK-293T cells. Cells were seeded in 12 -well plates at $5 \times 10^{4}$ cells/well. Cdca 7p reporter, ICN1, Mam, $d n-R B P j$, or irrelevant DNA and CMV- $\beta$-Galactosidase plasmids were transfected in triplicate. Cells were transfected using polyethylenimine (Polysciences, Inc.). To reduce endogenous ICN1 levels, HEK-293T cells were treated with $\gamma$-secretase inhibitor DAPT (EMD Millipore) at $50 \mu \mathrm{M}$ final concentration. 
Luciferase was measured $72 \mathrm{~h}$ after transfection according to the manufacturer's instructions (Luciferase Assay System; Promega). Expression levels of transfected proteins were verified by Western blot.

ChIP assay and ChIP-on-chip. Chromatin was obtained from a pool of 40 dissected AGMs at E11.5. ChIP was performed as previously described (Aguilera et al., 2004) with minor modifications. In brief, cross-linked chromatin from E10.5 or E11.5 dissected AGMs was sonicated for $10 \mathrm{~min}$, medium power, 0.5 interval with a Bioruptor (Diagenode) and precipitated with anti-RBPj (Chu and Bresnick, 2004), anti-ICN1 (Abcam), and antiMam (Santa Cruz Biotechnology, Inc.). After cross-linkage reversal, DNA was used as a template for PCR or for array hybridization. Mouse promoter ChIP-on-chip microarray SET (Agilent Technologies) was used to identify RBPj targets. It covers 70,000 best identified gene regions with a -5.5 - to $2.5-\mathrm{kb}$ range and has, on average, 25 probes per gene with a mean probe to probe distance of $200 \mathrm{bp}$. The ChIP-on-chip was performed with dye swaps and one $\operatorname{IgG}$ control was brought along. Enrichment analysis was done by comparing the precipitation normalized dye swap signal with input control signal. Alternatively, qPCR was performed with SYBR Green I Master (Roche) in the LightCycler480 system. Primers used are in Table S4.

ChIP-on-chip analysis. For calling the enriched peaks we used two independent algorithms, namely Chipper91 and Bioconductor92 package (version 2.7) iChIP (both iChIP1 and iChIP2; version 1.4.0). In the latter, background was corrected and Loess normalized data were used as input. For this purpose, the Bioconductor package Limma 93 was used. Multiple testcorrected (false discovery rate [FDR]; cutoff 0.05 for Chipper and 0.01 for iChIP) enriched probes were annotated to Ensembl (version 60) genes94. The RBPj target genes identified by both Chipper and iChIP were put in a highly confident $\mathrm{RBPj}$ targets dataset. Of this dataset, the region -5 to $5 \mathrm{~kb}$ from the TSS was scanned using the STORM program (version 9.4; 95) and Transfac RBPj position frequency matrix96 (using V\$RBPJK_01, M01112) for putative in silico RBPj binding site determination. GO (Ashburner et al., 2000) functional and pathway (KEGG) enrichment analysis of genes was done by using GiTools97. Functional annotation of differentially target genes is based on GO (Ashburner et al., 2000), as extracted from Ensembl (Hubbard et al., 2007) and KEGG pathway databases (Kanehisa et al., 2008). Accordingly, all genes are classified into the ontology categories biological process (GOBP) and pathways when possible. We have taken only the GO/ pathway categories that have at least 10 genes annotated. We used Gitools for enrichment analysis and heat map generation (Perez-Llamas and LopezBigas, 2011). Resulting p-values were adjusted for multiple testing using the Benjamini and Hochberg method of FDR (Benjamini et al., 2001). All data have been deposited in the GEO database (accession no. GSE52094; included in Table S1).

Cell culture, viral particle production, and viral infection. $32 \mathrm{D}$ cells were cultured in Iscove's and 10\% FBS supplemented with 10\% WeHiIL3-conditioned media. Hematopoietic cells from disrupted AGMs were incubated in Iscove's, 10\% FBS, and 10\% IL3- and 10\% stem cell factor (SCF)-conditioned medium plus $0.2 \mu \mathrm{g} / \mathrm{ml}$ IL6 and $0.1 \mu \mathrm{g} / \mathrm{ml}$ flt 3 . Recombinant lentiviruses were produced by transient transfection of HEK-293T. In brief, subconfluent HEK-293T were cotransfected with $20 \mu \mathrm{g}$ of transfer vector, $15 \mu \mathrm{g}$ of packaging plasmid (psPAX2), and $6 \mu \mathrm{g}$ of envelope plasmid (pMD2.G). After 3 d, supernatant was ultracentrifuged in a Beckman Coulter L-70 at $26,000 \mathrm{rpm}$ for $2 \mathrm{~h}$ at $4^{\circ} \mathrm{C}$ and viral pellet resuspended in $100 \mathrm{ml}$ PBS. Viruses were titrated in the 32D cell line, and the same amount of virus was used to infect the different conditions. Cultures were maintained for up to $12 \mathrm{~d}$. Cells were harvested by pipetting and examined for hematopoietic development by flow cytometry.

Hematopoietic colony assay (CFC). The dissected AGMs were digested in $0.12 \%$ collagenase (Sigma-Aldrich) in PBS supplemented with 10\% FBS for $20 \mathrm{~min}$ at $37^{\circ} \mathrm{C}$. AGM disrupted cells were cultured $7 \mathrm{~d}$ in Iscove's, $10 \%$ FBS, and 10\% IL3- and 10\% SCF-conditioned medium plus $0.2 \mu \mathrm{g} / \mathrm{ml} \mathrm{IL6}$ and $0.1 \mu \mathrm{g} / \mathrm{ml} \mathrm{flt3}$. Cells were infected with the same amount of infective particles (shControl or shCdca 7), and puromycin was added the following day. After $1 \mathrm{wk}$, cells were analyzed by FACS, and 3,000 cells from each condition were plated in duplicates in M-3434 semisolid medium (STEMCELL Technologies) to perform a CFC assay. After $7 \mathrm{~d}$, the presence of hematopoietic colonies was scored under the microscope.

Flow cytometry analysis and sorting. The AGM region was dissected from E10.5 embryos and dissociated in $0.12 \%$ collagenase (Sigma-Aldrich) in PBS supplemented with $10 \% \mathrm{FBS}$ for $20 \mathrm{~min}$ at $37^{\circ} \mathrm{C}$. The cells were analyzed by flow cytometry in a FACS Fortessa (BD). FlowJo software was used to analyze the results. Dead cells were excluded by DAPI. The antibodies CD31-PE, CD45-PECy7, and CD117-APC were purchased from BD. After staining for CD45, cells were fixed (Invitrogen) for cell cycle analysis, washed with PBS and 10\% FBS, and stained with anti-Ki67-APC (BD) in permeabilizing buffer (Invitrogen) for $20 \mathrm{~min}$ at room temperature. Then, cells were resuspened in PBS containing $2 \mu \mathrm{g} / \mathrm{ml}$ DAPI (Invitrogen). Annexin V staining was performed as indicated by the apoptosis detection kit (eBioscience), and cells were analyzed in binding buffer containing $5 \mu \mathrm{g} / \mathrm{ml}$ DAPI (Invitrogen). Cells were analyzed by flow cytometry.

ISH and immunofluorescence. For ISH, precisely timed embryos were fixed overnight at $4^{\circ} \mathrm{C}$ in $4 \%$ paraformaldehyde and subsequently embedded in OCT (Tissue-Tek). Embryos were sectioned in a Leica RM2135 cryostat at $16 \mu \mathrm{m}$. Digoxigenin (DIG)-labeled probes were generated from a pGEMT easy plasmid (Promega) containing Cdca 7 cDNA (75/1,220). $1.1 \mathrm{~kb}$ of Cdca 7 transcript was cloned using the following: forward, $5^{\prime}$-AAAGAATTCGAGGCTCGCCGCGCGC-3'; and reverse, 5'-AAACTCGAGCTACGCTTGCATTTCAAATTC- $3^{\prime}$. Images were acquired with an Olympus BX-60. For immunostaining, embryos at E10.5 and E11.5 were fixed overnight at $4^{\circ} \mathrm{C}$ in $37 \%$ formaldehyde and subsequently dehydrated with ethanol and embedded in paraffin. Anti-CDCA7 antibody was developed by AVIVA (ARP66756). Images were acquired in confocal microscope (Leica SP5). Representative images were edited on Adobe Photoshop CS4 software.

hESC hematopoietic cell differentiation and cell sorting. hESC-OP9 co-cultures were performed as previously described (Vodyanik and Slukvin, 2007) with some modifications (Real et al., 2012). In brief, OP9 stroma was prepared in gelatin-coated $10-\mathrm{cm}$ dishes in $\alpha$-MEM basal medium supplemented with $20 \%$ nonheat-inactivated FBS. The hESC lines AND1 and H9 grown in Matrigel-coated flasks were prepared as a suspension of small aggregates using Collagenase IV treatment followed by gentle scraping in differentiation medium (DM; $\alpha$-MEM basal medium, 10\% nonheat-inactivated FBS, $100 \mathrm{mM}$ monothioglycerol, and $50 \mathrm{mg} / \mathrm{ml}$ ascorbic acid) and plated on top of the 8-d OP9 stroma in $10 \mathrm{ml} \mathrm{DM}$. The next day, media were replaced by $20 \mathrm{ml} \mathrm{DM}$ to remove unattached cells; where indicated, we added $200 \mathrm{nM}$ Compound E (CompE; EMD Millipore) to block Notch activation. From day 3 of co-culture, a half-volume media change was performed every other day. At days 8 (for HEP purification) and 15 of co-culture (for $\mathrm{CD}^{4} 5^{+}$purification), cells were treated for $1 \mathrm{~h}$ with collagenase IV, followed by $20 \mathrm{~min}$ with Tryple (Gibco). Single cell suspensions were stained with anti-mouse CD29-FITC, anti-human CD31-PE, CD34-PE-Cy7, and CD45-APC antibodies, and human HEPs and $\mathrm{CD} 45^{+}$cells were purified by cell sorting as described above within the CD29- human population.

To allow hEB formation, undifferentiated hESCs were treated with collagenase IV and scraped off the Matrigel. These hESC clumps were transferred to low-attachment plates (Corning) and incubated overnight in DM (KO-DMEM), 20\% nonheat-inactivated FBS, 1\% nonessential amino acids, $1 \mathrm{mmol} / \mathrm{l} \mathrm{L}$-glutamine, and $0.1 \mathrm{mmol} / 1 \beta$-mercaptoethanol. From day 1 the media was changed every $3 \mathrm{~d}$ to the same DM supplemented with hematopoietic cytokines: $300 \mathrm{ng} / \mathrm{ml} \mathrm{SCF}, 300 \mathrm{ng} / \mathrm{ml} \mathrm{Flt3L}, 10 \mathrm{ng} / \mathrm{ml} \mathrm{IL-3,} 10 \mathrm{ng} / \mathrm{ml}$ IL-6, $50 \mathrm{ng} / \mathrm{ml} \mathrm{G-CSF}$, and $25 \mathrm{ng} / \mathrm{ml}$ bone morphogenetic protein 4 (BMP-4; Ramos-Mejia et al., 2012). At day 15 of differentiation, hEBs were dissociated using collagenase $\mathrm{B}$ (Roche) for $2 \mathrm{~h}$ at $37^{\circ} \mathrm{C}$, followed by 10-min incubation at $37^{\circ} \mathrm{C}$ with enzyme-free cell dissociation buffer (Invitrogen). 
The dissociated cells were stained as indicated above. Work with hESCs has been approved by the "Comisión Nacional de Control y Garantías" del Instituto de Salud Carlos III.

Zebrafish maintenance, morpholinos, microinjection and ISH. Embryos and adult fish were raised and maintained under standard laboratory conditions in the Erasmus Animal Facility (EDC). For the $c d c a 7$ probe, $c d c a 7$ full length was cloned from cDNA using the primers forward, $5^{\prime}$-TATTATGAATTCATGAACCTGCGGAGCTAC- $3^{\prime}$; and reverse, $5^{\prime}$-TATTATTCTAGATTATTCACTTTCCTCCAG- $3^{\prime}$. Subsequently, the $c d c a 7$ antisense probe was made using $500 \mathrm{bp}$ at the $3^{\prime}$ end of the gene using a digest of the natural Bgl1 restriction site in cdca7. DAPT treatment was performed according to Geling et al. (2002). Dechorionated embryos were treated at $6 \mathrm{~h}$ postfertilization (hpf) for $24 \mathrm{~h}$ in E3 containing either DMSO or DAPT. A $10-\mathrm{mM}$ stock (in DMSO) was diluted in $\mathrm{E} 3$ medium to a final concentration of $100 \mu \mathrm{M}$. Embryos were fixed in $4 \%$ paraformaldehyde containing sucrose for ISH.

An antisense splice blocking $\mathrm{MO}$ against $c d c a 7$ ( $3^{\prime}$-TACTGTAGATACAAACCATTTCTGT-5'), an ATG blocking MO against $c d c a 7$ ( $3^{\prime}$-AGCTCCTGTAGCTCCGCAGGTTCAT-5'), and $p 53$ have been previously described (Ma et al., 2012) and were purchased from Gene Tools. MOs $(4 \mathrm{ng})$ were injected alone or in combination with p53 MO into one-cellstage zebrafish embryos. MO knockdown was tested using the following primer sets: $c d c a 7$ forward, $3^{\prime}$-CAGACGAGAAGCTCCACTCA-5'; $c d c a 7$ reverse, 3'-TAGGCTCAGGCTTCACTGGT-5'; elfa qRT-PCR control: elfa forward, 3'-CTTCTCAGGCTGACTGTGC-5'; and elfa reverse, $3^{\prime}$ CCGCTAGCATTACCCTCC-5'. WISH for zebrafish embryos was performed at $30 \mathrm{hpf}$ as described previously (Patterson et al., 2005). The CD41-GFP and CD41-GFP/Flt1-RFP imaging was performed at $50 \mathrm{hpf}$ and the area imaged was the CHT. cmyb, gridlock ( $g r l)$, and ephrinB2a probes (Thompson et al., 1998) and CD41-GFP (Lin et al., 2005) were used as markers for HSCs in zebrafish. Flt1-RFP was used as a marker for arterial cells (Bussmann et al., 2010). CD41-GFP and Flt1-RFP transgenic zebrafish were kept in a homozygous state. Significance was determined by the Student's $t$ test.

Online supplemental material. Fig. S1 shows that Hes1 predicted RBPjbinding sites. Fig. S2 shows $\mathrm{Cdca} 7$ is expressed in human and mouse hematopoietic progenitors. Table S1, included as a separate PDF file, shows Chipper- and iChip-identified RBPj target genes. Tables S2 and S3 show mouse and human expression RT-PCR primers, respectively. Table S4 shows promoter mouse primers. Online supplemental material is available at http:// www.jem.org/cgi/content/full/jem.20131857/DC1.

We thank E.H. Bresnick (University of Wisconsin, Madison, WI) for the anti-RBPj antibody; Leonard Zon and Michelle I. Lin (Harvard Medical School, Boston, MA) for sharing unpublished ChIP-seq data; the microarray facility, animal facility, and flow cytometry facility at Parc de Recerca Biomèdica de Barcelona for technical assistance; Alba Placin and Vera Horvath for technical contribution to the project; Miguel Campanero (Instituto de Investigaciones Biomédicas, Madrid, Spain) and Pedro Real (GENIO, Seville, Spain) for support; and the members of the Bigas laboratory for helpful discussions.

J. Guiu was a recipient of Formación Personal Investigador (FPI) BES-2008005708. This research was funded by grants from the Ministerio de Economia y Competitividad, FEDER (SAF2007-60080, PLE2009-0111, SAF2010-15450, and SAF2013-40922R), Red Temática de Investigación Cooperativa en Cáncer (RTICC; RD06/0020/0098 and RD12/0036/0054), Association for International Cancer Research (AICR; 13-0064), Agència de Gestió d'Ajuds Universitaris i de Recerca (AGAUR; 2009SGR-23, CONES2010-0006) to A. Bigas, the Spanish Association against Cancer Research (AECC) to A. Bigas and P. Menendez, Fondo de Investigación Sanitaria (FIS; PI10/00449) to P. Menendez, and ZonMW TOP (40-00812-98-11068) to E. Dzierzak and E. De Pater.

The authors declare no competing financial interests.

Submitted: 4 September 2013

Accepted: 10 October 2014

\section{REFERENCES}

Aguilera, C., R. Hoya-Arias, G. Haegeman, L. Espinosa, and A. Bigas. 2004. Recruitment of IкB $\alpha$ to the hes 1 promoter is associated with transcriptional repression. Proc. Natl. Acad. Sci. USA. 101:16537-16542. http://dx.doi.org/10.1073/pnas.0404429101

Arnett, K.L., M. Hass, D.G. McArthur, M.X. Ilagan, J.C. Aster, R. Kopan, and S.C. Blacklow. 2010. Structural and mechanistic insights into cooperative assembly of dimeric Notch transcription complexes. Nat. Struct. Mol. Biol. 17:1312-1317. http://dx.doi.org/10.1038/nsmb.1938

Ashburner, M., C.A. Ball, J.A. Blake, D. Botstein, H. Butler, J.M. Cherry, A.P. Davis, K. Dolinski, S.S. Dwight, J.T. Eppig, et al. The Gene Ontology Consortium. 2000. Gene ontology: tool for the unification of biology. Nat. Genet. 25:25-29. http://dx.doi.org/10.1038/75556

Benjamini, Y., D. Drai, G. Elmer, N. Kafkafi, and I. Golani. 2001. Controlling the false discovery rate in behavior genetics research. Behav. Brain Res. 125:279-284. http://dx.doi.org/10.1016/S0166-4328(01)00297-2

Bertrand, J.Y., A.D. Kim, S. Teng, and D. Traver. 2008. CD $41^{+} \mathrm{cmyb}^{+}$ precursors colonize the zebrafish pronephros by a novel migration route to initiate adult hematopoiesis. Development. 135:1853-1862. http://dx .doi.org/10.1242/dev.015297

Bertrand, J.Y., J.L. Cisson, D.L. Stachura, and D. Traver. 2010. Notch signaling distinguishes 2 waves of definitive hematopoiesis in the zebrafish embryo. Blood.115:2777-2783.http://dx.doi.org/10.1182/blood-200909-244590

Bigas, A., and L. Espinosa. 2012. Hematopoietic stem cells: to be or Notch to be. Blood. 119:3226-3235. http://dx.doi.org/10.1182/blood-2011$10-355826$

Bueno, C., V. Ayllón, R. Montes, O. Navarro-Montero, V. Ramos-Mejia, P.J. Real, D. Romero-Moya, M.J. Araúzo-Bravo, and P. Menendez. 2013. FLT3 activation cooperates with MLL-AF4 fusion protein to abrogate the hematopoietic specification of human ESCs. Blood. 121: 3867-3878. http://dx.doi.org/10.1182/blood-2012-11-470146

Burns, C.E., D. Traver, E. Mayhall, J.L. Shepard, and L.I. Zon. 2005. Hematopoietic stem cell fate is established by the Notch-Runx pathway. Genes Dev. 19:2331-2342. http://dx.doi.org/10.1101/gad.1337005

Bussmann, J., F.L. Bos, A. Urasaki, K. Kawakami, H.J. Duckers, and S. Schulte-Merker. 2010. Arteries provide essential guidance cues for lymphatic endothelial cells in the zebrafish trunk. Development. 137:26532657. http://dx.doi.org/10.1242/dev.048207

Chen, M.J., T. Yokomizo, B.M. Zeigler, E. Dzierzak, and N.A. Speck. 2009. Runx1 is required for the endothelial to haematopoietic cell transition but not thereafter. Nature. 457:887-891. http://dx.doi.org/10.1038/ nature 07619

Chu, J., and E.H. Bresnick. 2004. Evidence that C promoter-binding factor 1 binding is required for Notch-1-mediated repression of activator protein-1.J. Biol. Chem. 279:12337-12345. http://dx.doi.org/10.1074/ jbc.M311510200

Ciau-Uitz, A., R. Monteiro, A. Kirmizitas, and R. Patient. 2014. Developmental hematopoiesis: ontogeny, genetic programming and conservation. Exp. Hematol. 42:669-683. http://dx.doi.org/10.1016/j.exphem .2014 .06 .001

Duarte, A., M. Hirashima, R. Benedito, A. Trindade, P. Diniz, E. Bekman, L. Costa, D. Henrique, and J. Rossant. 2004. Dosage-sensitive requirement for mouse Dll4 in artery development. Genes Dev. 18:2474-2478. http://dx.doi.org/10.1101/gad.1239004

Geling, A., H. Steiner, M. Willem, L. Bally-Cuif, and C. Haass. 2002. A $\gamma$-secretase inhibitor blocks Notch signaling in vivo and causes a severe neurogenic phenotype in zebrafish. EMBO Rep. 3:688-694. http:// dx.doi.org/10.1093/embo-reports/kvf124

Goto, Y., R. Hayashi, T. Muramatsu, H. Ogawa, I. Eguchi, Y. Oshida, K. Ohtani, and K. Yoshida. 2006. JPO1/CDCA7, a novel transcription factor E2F1-induced protein, possesses intrinsic transcriptional regulator activity. Biochim. Biophys. Acta. 1759:60-68. http://dx.doi.org/10.1016/ j.bbaexp.2006.02.004

Guiu, J., R. Shimizu, T. D’Altri, S.T. Fraser, J. Hatakeyama, E.H. Bresnick, R. Kageyama, E. Dzierzak, M. Yamamoto, L. Espinosa, and A. Bigas. 2013. Hes repressors are essential regulators of hematopoietic stem cell development downstream of Notch signaling. J. Exp. Med. 210:71-84. http://dx.doi.org/10.1084/jem.20120993 
Haggerty, T.J., K.I. Zeller, R.C. Osthus, D.R. Wonsey, and C.V. Dang. 2003. A strategy for identifying transcription factor binding sites reveals two classes of genomic c-Myc target sites. Proc. Natl. Acad. Sci. USA. 100:5313-5318. http://dx.doi.org/10.1073/pnas.0931346100

Hubbard, T.J., B.L. Aken, K. Beal, B. Ballester, M. Caccamo, Y. Chen, L. Clarke, G. Coates, F. Cunningham, T. Cutts, et al. 2007. Ensembl 2007. Nucleic Acids Res. 35:D610-D617. http://dx.doi.org/10.1093/nar/ gk1996

Ivanovs, A., S. Rybtsov, L. Welch, R.A. Anderson, M.L. Turner, and A. Medvinsky. 2011. Highly potent human hematopoietic stem cells first emerge in the intraembryonic aorta-gonad-mesonephros region. J. Exp. Med. 208:2417-2427. http://dx.doi.org/10.1084/jem.20111688

Kanehisa, M., M. Araki, S. Goto, M. Hattori, M. Hirakawa, M. Itoh, T. Katayama, S. Kawashima, S. Okuda, T. Tokimatsu, and Y. Yamanishi. 2008. KEGG for linking genomes to life and the environment. Nucleic Acids Res. 36:D480-D484. http://dx.doi.org/10.1093/nar/gkm882

Konuma, T., S. Nakamura, S. Miyagi, M. Negishi, T. Chiba, H. Oguro, J. Yuan, M. Mochizuki-Kashio, H. Ichikawa, H. Miyoshi, et al. 2011. Forced expression of the histone demethylase Fbxl10 maintains selfrenewing hematopoietic stem cells. Exp. Hematol. 39:697-709: e5. http:// dx.doi.org/10.1016/j.exphem.2011.03.008

Krebs, L.T., J.R. Shutter, K. Tanigaki, T. Honjo, K.L. Stark, and T. Gridley. 2004. Haploinsufficient lethality and formation of arteriovenous malformations in Notch pathway mutants. Genes Dev. 18:2469-2473. http:// dx.doi.org/10.1101/gad.1239204

Krejcí, A., and S. Bray. 2007. Notch activation stimulates transient and selective binding of $\mathrm{Su}(\mathrm{H}) / \mathrm{CSL}$ to target enhancers. Genes Dev. 21:13221327. http://dx.doi.org/10.1101/gad.424607

Kumano, K., S. Chiba, A. Kunisato, M. Sata, T. Saito, E. NakagamiYamaguchi, T. Yamaguchi, S. Masuda, K. Shimizu, T. Takahashi, et al. 2003. Notch1 but not Notch2 is essential for generating hematopoietic stem cells from endothelial cells. Immunity. 18:699-711. http://dx.do .org/10.1016/S1074-7613(03)00117-1

Lawson, N.D., and B.M. Weinstein. 2002. Arteries and veins: making a difference with zebrafish. Nat. Rev. Genet. 3:674-682. http://dx.doi . org $/ 10.1038 / \mathrm{nrg} 888$

Lee, J.B., T.E. Werbowetski-Ogilvie, J.H. Lee, B.A. McIntyre, A. Schnerch, S.H. Hong, I.H. Park, G.Q. Daley, I.D. Bernstein, and M. Bhatia. 2013. Notch-HES1 signaling axis controls hemato-endothelial fate decisions of human embryonic and induced pluripotent stem cells. Blood. 122:1162-1173. http://dx.doi.org/10.1182/blood-2012-12-471649

Lin, H.F., D. Traver, H. Zhu, K. Dooley, B.H. Paw, L.I. Zon, and R.I Handin. 2005. Analysis of thrombocyte development in CD41-GFP transgenic zebrafish. Blood. 106:3803-3810. http://dx.doi.org/10.1182/ blood-2005-01-0179

Ma, D., L. Wang, S. Wang, Y. Gao, Y. Wei, and F. Liu. 2012. Foxn1 maintains thymic epithelial cells to support T-cell development via $\mathrm{mcm} 2$ in zebrafish. Proc. Natl. Acad. Sci. USA. 109:21040-21045. http://dx.doi .org/10.1073/pnas.1217021110

Mandal, L., U. Banerjee, and V. Hartenstein. 2004. Evidence for a fruit fly hemangioblast and similarities between lymph-gland hematopoiesis in fruit fly and mammal aorta-gonadal-mesonephros mesoderm. Nat. Genet. 36:1019-1023. http://dx.doi.org/10.1038/ng1404

McKinney-Freeman, S., P. Cahan, H. Li, S.A. Lacadie, H.T. Huang, M. Curran, S. Loewer, O. Naveiras, K.L. Kathrein, M. Konantz, et al. 2012. The transcriptional landscape of hematopoietic stem cell ontogeny. Cell Stem Cell. 11:701-714. http://dx.doi.org/10.1016/j.stem 2012.07 .018

Osthus, R.C., B. Karim, J.E. Prescott, B.D. Smith, M. McDevitt, D.L. Huso, and C.V. Dang. 2005. The Myc target gene JPO1/CDCA7 is frequently overexpressed in human tumors and has limited transforming activity in vivo. Cancer Res. 65:5620-5627. http://dx.doi.org/10.1158/ 0008-5472.CAN-05-0536

Patterson, L.J., M. Gering, and R. Patient. 2005. Scl is required for dorsal aorta as well as blood formation in zebrafish embryos. Blood. 105:35023511. http://dx.doi.org/10.1182/blood-2004-09-3547

Perez-Llamas, C., and N. Lopez-Bigas. 2011. Gitools: analysis and visualisation of genomic data using interactive heat-maps. PLoS ONE. 6:e19541. http://dx.doi.org/10.1371/journal.pone.0019541
Rafii, S., C.C. Kloss, J.M. Butler, M. Ginsberg, E. Gars, R. Lis, Q. Zhan, P. Josipovic, B.S. Ding, J. Xiang, et al. 2013. Human ESC-derived hemogenic endothelial cells undergo distinct waves of endothelial to hematopoietic transition. Blood. 121:770-780. http://dx.doi.org/10.1182/ blood-2012-07-444208

Ramos-Mejia, V., C. Bueno, M. Roldan, L. Sanchez, G. Ligero, P. Menendez, and M. Martin. 2012. The adaptation of human embryonic stem cells to different feeder-free culture conditions is accompanied by a mitochondrial response. Stem Cells Dev. 21:1145-1155. http://dx.doi .org/10.1089/scd.2011.0248

Real, P.J., G. Ligero, V. Ayllon, V. Ramos-Mejia, C. Bueno, I. GutierrezAranda, O. Navarro-Montero, M. Lako, and P. Menendez. 2012. SCL/ TAL1 regulates hematopoietic specification from human embryonic stem cells. Mol. Ther. 20:1443-1453. http://dx.doi.org/10.1038/mt.2012.49

Robert-Moreno, A., L. Espinosa, J.L. de la Pompa, and A. Bigas. 2005. RBPјк-dependent Notch function regulates Gata2 and is essential for the formation of intra-embryonic hematopoietic cells. Development. 132:1117-1126. http://dx.doi.org/10.1242/dev.01660

Robert-Moreno, A., L. Espinosa, M.J. Sanchez, J.L. de la Pompa, and A. Bigas. 2007. The notch pathway positively regulates programmed cell death during erythroid differentiation. Leukemia. 21:1496-1503. http:// dx.doi.org/10.1038/sj.leu.2404705

Robert-Moreno, A., J. Guiu, C. Ruiz-Herguido, M.E. López, J. InglésEsteve, L. Riera, A. Tipping, T. Enver, E. Dzierzak, T. Gridley, et al. 2008. Impaired embryonic haematopoiesis yet normal arterial development in the absence of the Notch ligand Jagged1. EMBO J. 27:18861895. http://dx.doi.org/10.1038/emboj.2008.113

Ruiz-Herguido, C., J. Guiu, T. D’Altri, J. Inglés-Esteve, E. Dzierzak, L. Espinosa, and A. Bigas. 2012. Hematopoietic stem cell development requires transient Wnt/ $\beta$-catenin activity. J. Exp. Med. 209:1457-1468. http://dx.doi.org/10.1084/jem.20120225

Schroeder, T., S.T. Fraser, M. Ogawa, S. Nishikawa, C. Oka, G.W. Bornkamm, S. Nishikawa, T. Honjo, and U. Just. 2003. Recombination signal sequence-binding protein JK alters mesodermal cell fate decisions by suppressing cardiomyogenesis. Proc. Natl. Acad. Sci. USA. 100:40184023. http://dx.doi.org/10.1073/pnas. 0438008100

Taoudi, S., C. Gonneau, K. Moore, J.M. Sheridan, C.C. Blackburn, E. Taylor, and A. Medvinsky. 2008. Extensive hematopoietic stem cell generation in the AGM region via maturation of VE-cadherin ${ }^{+} \mathrm{CD} 45^{+}$predefinitive HSCs. Cell Stem Cell. 3:99-108. http://dx.doi.org/10.1016/ j.stem.2008.06.004

Terriente-Felix, A., J. Li, S. Collins, A. Mulligan, I. Reekie, F. Bernard, A. Krejci, and S. Bray. 2013. Notch cooperates with Lozenge/Runx to lock haemocytes into a differentiation programme. Development. 140:926-937. http://dx.doi.org/10.1242/dev.086785

Thisse, B., S. Pflumio, M. Fürthauer, B. Loppin, V. Heyer, A. Degrave, R. Woehl, A. Lux, T. Steffan, X.Q. Charbonnier, and C. Thisse. 2001 Expression of the zebrafish genome during embryogenesis. ZFIN, University of Oregon, Eugene, OR. Available at: http://zfin.org/ ZDB-PUB-010810-1 (accessed March 11, 2014).

Thompson, M.A., D.G. Ransom, S.J. Pratt, H. MacLennan, M.W. Kieran, H.W. Detrich III, B. Vail, T.L. Huber, B. Paw, A.J. Brownlie, et al 1998. The cloche and spadetail genes differentially affect hematopoiesis and vasculogenesis. Dev. Biol. 197:248-269. http://dx.doi.org/10.1006/ dbio.1998.8887

van der Flier, L.G., M.E. van Gijn, P. Hatzis, P. Kujala, A. Haegebarth, D.E. Stange, H. Begthel, M. van den Born, V. Guryev, I. Oving, et al. 2009. Transcription factor achaete scute-like 2 controls intestinal stem cell fate. Cell. 136:903-912. http://dx.doi.org/10.1016/j.cell.2009.01.031

Vodyanik, M.A., and I.I. Slukvin. 2007. Hematoendothelial differentiation of human embryonic stem cells. Curr. Protoc. Cell Biol. Chapter 23:Unit 23.6.

Wang, L., L. Li, F. Shojaei, K. Levac, C. Cerdan, P. Menendez, T. Martin, A. Rouleau, and M. Bhatia. 2004. Endothelial and hematopoietic cell fate of human embryonic stem cells originates from primitive endothelium with hemangioblastic properties. Immunity. 21:31-41. http://dx .doi.org/10.1016/j.immuni.2004.06.006

Warga, R.M., D.A. Kane, and R.K. Ho. 2009. Fate mapping embryonic blood in zebrafish: multi- and unipotential lineages are segregated at gastrulation. Dev. Cell. 16:744-755. http://dx.doi.org/10.1016/j.devcel.2009.04.007 
Whitfield, M.L., G. Sherlock, A.J. Saldanha, J.I. Murray, C.A. Ball, K.E. Alexander, J.C. Matese, C.M. Perou, M.M. Hurt, P.O. Brown, and D. Botstein. 2002. Identification of genes periodically expressed in the human cell cycle and their expression in tumors. Mol. Biol. Cell. 13:19772000. http://dx.doi.org/10.1091/mbc.02-02-0030

Xue, Y., X. Gao, C.E. Lindsell, C.R. Norton, B. Chang, C. Hicks, M. Gendron-Maguire, E.B. Rand, G. Weinmaster, and T. Gridley. 1999. Embryonic lethality and vascular defects in mice lacking the Notch ligand Jagged1. Hum. Mol. Genet. 8:723-730. http://dx.doi.org/10.1093/ $\mathrm{hmg} / 8.5 .723$

Yokomizo, T., and E. Dzierzak. 2010. Three-dimensional cartography of hematopoietic clusters in the vasculature of whole mouse embryos. Development. 137:3651-3661. http://dx.doi.org/10.1242/dev.051094
You, L.R., F.J. Lin, C.T. Lee, F.J. DeMayo, M.J. Tsai, and S.Y. Tsai. 2005. Suppression of Notch signalling by the COUP-TFII transcription factor regulates vein identity. Nature. 435:98-104. http://dx.doi .org/10.1038/nature03511

Yu, X., J. Zou, Z. Ye, H. Hammond, G. Chen, A. Tokunaga, P. Mali, Y.M. Li, C. Civin, N. Gaiano, and L. Cheng. 2008. Notch signaling activation in human embryonic stem cells is required for embryonic, but not trophoblastic, lineage commitment. Cell Stem Cell. 2:461-471. http://dx.doi.org/10.1016/j.stem.2008.03.001

Zovein, A.C., J.J. Hofmann, M. Lynch, W.J. French, K.A. Turlo, Y. Yang, M.S. Becker, L. Zanetta, E. Dejana, J.C. Gasson, et al. 2008. Fate tracing reveals the endothelial origin of hematopoietic stem cells. Cell Stem Cell. 3:625-636. http://dx.doi.org/10.1016/j.stem.2008.09.018 